\title{
Modelling unsaturated soil behaviour during normal consolidation and at critical state
}

\author{
Domenico Gallipoli ${ }^{\mathrm{a}, *}$, Antonio Gens ${ }^{\mathrm{b}}$, Guangjing Chen ${ }^{\mathrm{c}}$, Francesca D’Onza ${ }^{\mathrm{a}}$ \\ a University of Glasgow, Department of Civil Engineering, Rankine Building, Oakfield Avenue, G12 8LT Glasgow, United Kingdom \\ ${ }^{\mathrm{b}}$ Universitat Politècnica de Catalunya, Department of Geotechnical Engineering and Geosciences, Jordi Girona 1-3, Edifici D-2, 08034 Barcelona, Spain \\ ${ }^{\mathrm{c}}$ European Underground Research Infrastructure for Disposal of Nuclear Waste in Clay Environment (EURIDICE), 2400 Mol, Belgium
}

\section{A R T I C L E I N F O}

Article history:

Available online 26 September 2008

Keywords:

Soil mechanics

Constitutive modelling

Partial saturation

Plasticity

Suction

\begin{abstract}
A B S T R A C T
An analysis of results from published laboratory tests on Jossigny silt and Barcelona clayey silt is presented to confirm the existence of a unique capillary bonding function linking the quotient between unsaturated and saturated void ratio, at the same mean average skeleton stress, to a single capillary bonding scalar variable. The analysis confirms that the same capillary bonding function applies to both normally consolidated and critical stress states.

The above two experimental sets with the addition of further published data for Speswhite Kaolin are also used to study the relationship between unsaturated critical shear strength, mean average skeleton stress and capillary bonding variable. The results of such analysis are assessed in the light of a similar modelling framework proposed in the literature.
\end{abstract}

(c) 2008 Elsevier Ltd. All rights reserved.

\section{Introduction}

Early research on the fundamental behaviour of unsaturated soil (e.g. [3]) attempted to relate the mechanical behaviour of this material to a single effective stress $\sigma_{h k}^{\prime}$ of the form:

$\boldsymbol{\sigma}_{h k}^{\prime}=\boldsymbol{\sigma}_{h k}-\delta_{h k}\left[u_{\mathrm{a}}-\boldsymbol{\chi}\left(u_{\mathrm{a}}-u_{\mathrm{w}}\right)\right]$

where $\sigma_{h k}$ is the total stress, $u_{\mathrm{a}}$ is the air pressure, $u_{\mathrm{w}}$ is the liquid pressure, $\delta_{h k}$ is Kronecker's delta and $\chi$ is a soil parameter depending on degree of saturation and ranging from zero, when the soil is dry, to unity, when the soil is saturated. Eq. (1) is probably the simplest and most intuitive way of generalizing the principle of effective stress postulated by Terzaghi [19] for saturated soils to the unsaturated domain. Indeed Eq. (1) reduces to the definition of the saturated effective stress when the degree of saturation, and hence the parameter $\chi$, becomes equal to unity. The debate on the existence of a single effective stress variable in unsaturated soils, as it is the case for saturated soils, has traditionally been linked to the analysis of two distinct aspects of behaviour, i.e. deformation and shear strength.

In [9], Jennings and Burland described the difficulties of modelling important characteristic of the volumetric behaviour of unsaturated soils by using only one effective stress as a constitutive variable. In [4], Bishop and Blight observed that the parameter $\chi$ in Eq. (1) is linked to the degree of saturation via a relationship that

\footnotetext{
* Corresponding author.

E-mail address: gallipoli@civil.gla.ac.uk (D. Gallipoli).
}

depends not only on the type of soil but also on the particular stress path being followed. This is a significant limitation to the formulation of a general constitutive model for unsaturated soils in terms of a single effective stress. This was indeed recognized by Bishop and Blight [4], who however concluded that the effective stress defined by Eq. (1) “... .can be used with much less difficulty in terms of shear strength ... than in terms of volume change...”.

Eq. (1) provides an approximate measure of the average stress acting on the unsaturated soil skeleton by weighing the pore pressures exerted by both liquid and gas $[8,13]$. The use of Eq. (1) as a single effective stress variable is however difficult because the mechanical response of an unsaturated soil is governed not only by the change of the average stress acting on the solid skeleton but also by the change of the soil "structure" associated to the inter-particle capillary bonding generated by water menisci. A stress-strain model formulated in terms of a single effective stress variable, such as that given by Eq. (1), is potentially capable of capturing the former effect but not the latter one.

A number of constitutive models for unsaturated soils have been proposed during recent years where the bonding exerted by water menisci at inter-particle contacts has been accounted for by introducing a scalar constitutive variable in addition to a tensorial stress variable. The form of stress variable is not unique and various alternatives of Eq. (1) have been proposed where $\chi$ is a function of degree of saturation or suction or both, e.g. Nuth and Laloui [15], Karube and Kawai [11], Loret and Khalili [14]. The most commonly used stress variable is the net stress, e.g. Alonso et al. [1], given by Eq. (1) where $\chi$ is equal to zero. The additional scalar 
variable is usually suction e.g. [1] or degree of saturation e.g. [18] or a combination of these two e.g. [7].

Consistently with the above physical argument, Gallipoli et al. [7] presented a constitutive model formulated in terms of one tensorial variable and one scalar variable. This model is capable of predicting elasto-plastic volumetric changes in an unsaturated soil that is either normally consolidated or at critical state.

The tensorial variable is the "average skeleton stress" $\sigma_{h k}^{\prime \prime}$ defined as the stress given by Eq. (1) with the parameter $\chi$ equal to the degree of saturation $S_{\mathrm{r}}[10]$ :

$\sigma_{h k}^{\prime \prime}=\sigma_{h k}-\delta_{h k}\left[u_{\mathrm{a}}-S_{\mathrm{r}}\left(u_{\mathrm{a}}-u_{\mathrm{w}}\right)\right]$

The scalar variable is the capillary bonding $\xi$ defined in terms of degree of saturation $S_{\mathrm{r}}$ and suction $s$ :

$\xi=f(s)\left(1-S_{\mathrm{r}}\right)$

Eq. (3) is based on the postulate that capillary bonding depends on two factors, namely the number of inter-particle water menisci per unit volume of solid and the degree of inter-particle pull generated by the suction within each water meniscus. Under the simplifying assumptions introduced by Gallipoli et al. [7], the former factor is uniquely related to the variable $\left(1-S_{\mathrm{r}}\right)$ whereas the latter factor is described by the variable $f(s)$, which is a function of suction based on the simplified capillary model of Fisher [6]. The capillary bonding $\xi$ defined by Eq. (3) combines both the above factors in a single measure defined as the product of the corresponding variables $\left(1-S_{\mathrm{r}}\right)$ and $f(S)$

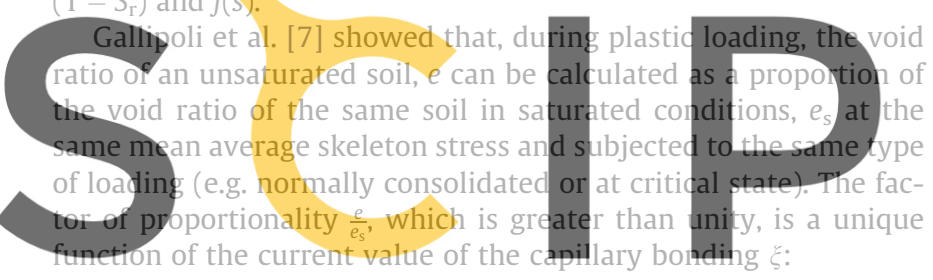

Register for free at https//www.scipedia.com to The function of Eq. (4), which for simplicity we will name "capillary bonding function" in the following part of this paper, also appears to be the same for soil samples that are normally consolidated or at critical state.

A single capillary bonding function is therefore necessary to extend the application of saturated soil models to the domain of unsaturated soils and this only requires a limited number of additional model parameters. Another appealing feature of the proposal by Gallipoli et al. [7] is the unified interpretation of irreversible volumetric strains in terms of a single yield curve regardless whether irreversible strains are caused by loading, wetting or drying (see also [23]). The ability to capture irreversible strains by activating the same yield locus during drying as well as during loading or wetting is a significant improvement over previous constitutive frameworks such as, for example, the "Barcelona Basic Model" of Alonso et al. [1].

The first part of this paper provides additional validation of the assumptions introduced by Gallipoli et al. [7] for modelling volumetric strains against experimental data from laboratory tests on Jossigny silt performed by Cui [5] and Barcelona clayey silt performed by Barrera [2]. In the second part of the paper the effect of partial saturation on soil strength at critical state is analysed in the light of the previous two data sets as well as additional results from tests on Speswhite Kaolin performed by Sivakumar [17] and Wheeler and Sivakumar [24]. In particular, the dependency of the unsaturated critical state strength on the capillary bonding $\xi$ is explored and compared with the dependency of volumetric strains on the same variable.

\section{Validation of modelling assumptions by Gallipoli et al. [7]}

Gallipoli et al. [7] assumed that during plastic loading of an unsaturated soil element the quotient between the current void ratio $e$ and the void ratio $e_{\mathrm{s}}$ in saturated conditions, at corresponding values of the average skeleton stress, is a unique function of the capillary bonding $\xi$. This modelling assumption has been validated by Gallipoli et al. [7] for normally consolidated and critical stress states by using data from laboratory tests performed on three unsaturated soils, i.e. a compacted Speswhite Kaolin clay [17] and [24], a compacted mixture of Bentonite and Kaolin clays [16] and a compacted Kiunyu gravel [20]. Gallipoli et al. [7] also postulated that the capillary bonding function is a property of the soil and, based on the same set of data, they demonstrated the uniqueness of such function for both normally consolidated and critical states.

In this paper, the modelling assumption by Gallipoli et al. [7] will be further validated against results from laboratory tests on two other types of unsaturated soil samples, i.e. Jossigny silt samples [5] prepared by one-dimensional static compaction to a dry density of $1.67 \mathrm{~g} / \mathrm{cm}^{3}$ and a water content of $18 \%$ (which correspond approximately to the Proctor optimum) and Barcelona clayey silt samples [2] prepared by isotropic static compression to $600 \mathrm{kPa}$ at a water content of $11 \%$ (this results in a dry density of $1.65 \mathrm{~g} / \mathrm{cm}^{3}$, which corresponds to dry of optimum on the isotropic static compaction curve at $600 \mathrm{kPa}$ ). These two unsaturated silts have intermediate grain size between the clays and gravels considered in the original paper by

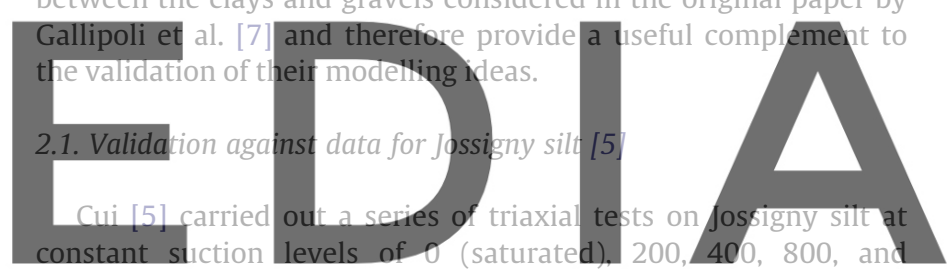

$1500 \mathrm{kPa}$. A number of samples were sheared to critical state at each value of suction, after consolidațion to variable levels of mean gewatralsad the version without the watermark

The data by Cui [5] are here used to validate the model of Gallipoli et al. [7] by defining the capillary bonding function with reference to critical states (it is here assumed that all shearing stages performed by Cui [5] take soil samples to critical state). Such capillary bonding function is subsequently used it to predict soil behaviour at normally consolidated states.

For the definition of the capillary bonding function, it is first necessary to identify the reference saturated critical state line in terms of void ratio and mean average skeleton stress. Given that Cui [5] presents only two saturated shearing tests at a suction of $0 \mathrm{kPa}$, the results from two additional shearing tests at suction of $200 \mathrm{kPa}$ have been considered in this work to improve estimation of the saturated critical state line. Such two additional tests achieve, at the end of shearing, values of the degree of saturation of $92 \%$ and $98 \%$, respectively and are therefore considered to be representative of the saturated soil behaviour. In summary, the saturated critical state line is calculated on the basis of four experimental points (i.e. two at a suction of $0 \mathrm{kPa}$ and two at a suction of $200 \mathrm{kPa}$ ) as

$e_{\mathrm{s}}=\Gamma-\psi \cdot \ln p^{\prime \prime}$

where $p^{\prime \prime}$ is the mean average skeleton stress (coinciding with Terzaghis mean effective stress for a saturated soil), $e_{\mathrm{s}}$ is the saturated void ratio and the values of the parameters $\Gamma$ and $\psi$ are equal to 1.13 and 0.0932 , respectively. Fig. 1 shows such critical state line together with the four critical state points used for its definition. Fig. 1 also shows additional points representing the unsaturated critical states achieved during shearing stages performed by Cui [5] at various values of suction. 


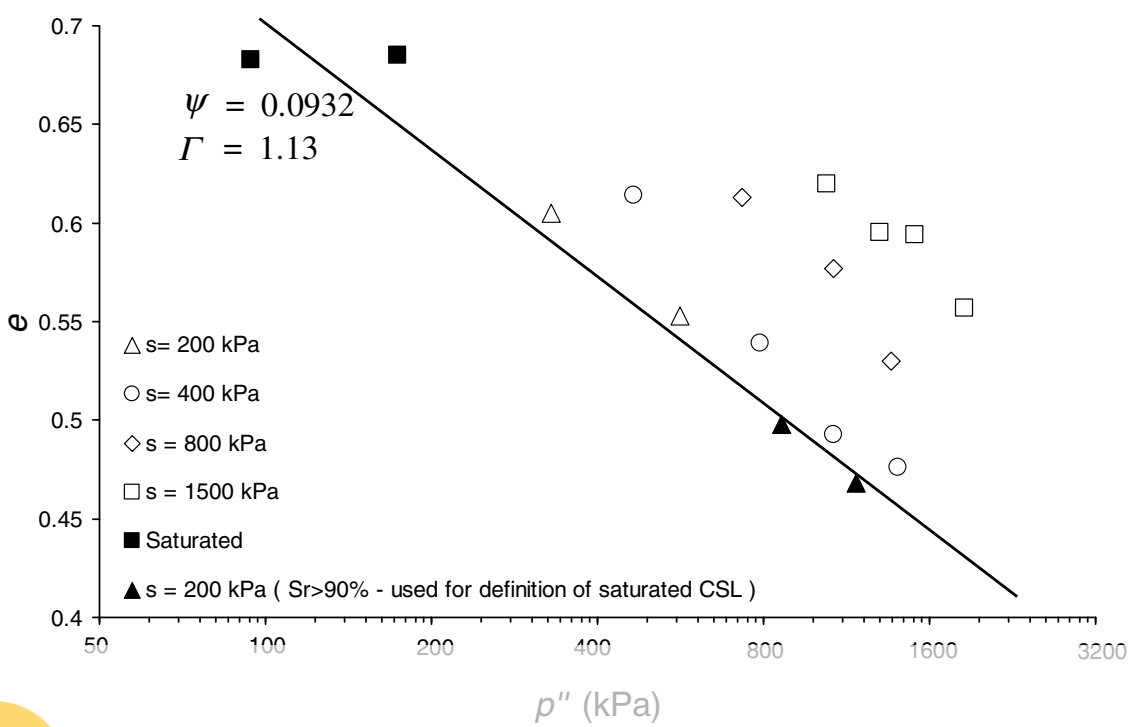

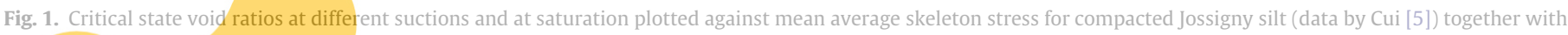
interpolated saturated critical state line.

Fig. 2 plots the quotients $\frac{e}{e_{s}}$ between unsaturated and saturated critical state void ratios (where the saturated void ratio is calculated according to Eq. (5) at the same average skeleton stress as

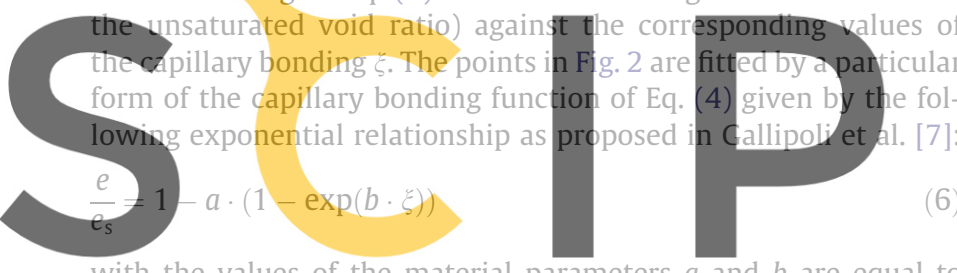

with the values of the material parameters $a$ and $b$ are equal to 0.0173 and 6.53, respectively.

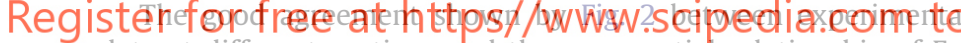
data at different suctions and the exponential relationship of Eq. (6) provides further proof of the existence of a capillary bonding function as postulated by Gallipoli et al. [7]. Note that the circied points in Fig. 2 refer to those tests where the deviator stress passes through a peak during shearing and strain localization is likely to occur during the post-peak phase. For these tests it is questionable whether the degree of saturation and void ratio measured at the end of shearing are representative of a homogenous sample. The corresponding points in Fig. 1 have therefore been neglected when

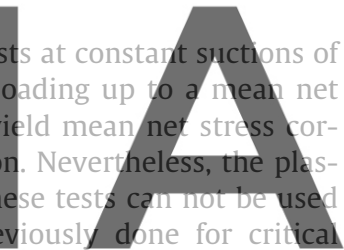
states, because the saturated normal compression line is unknown and water content values are only reported at the end

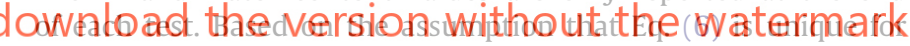
critical and normally consolidated stress states, it is however possible to estimate the saturated void ratio corresponding to the mean average skeleton stress at the end of each of these four tests. The results of such analysis are summarized in Fig. 3 where the measured void ratios at the end of the four tests are shown together with the corresponding estimated saturated void ratios.

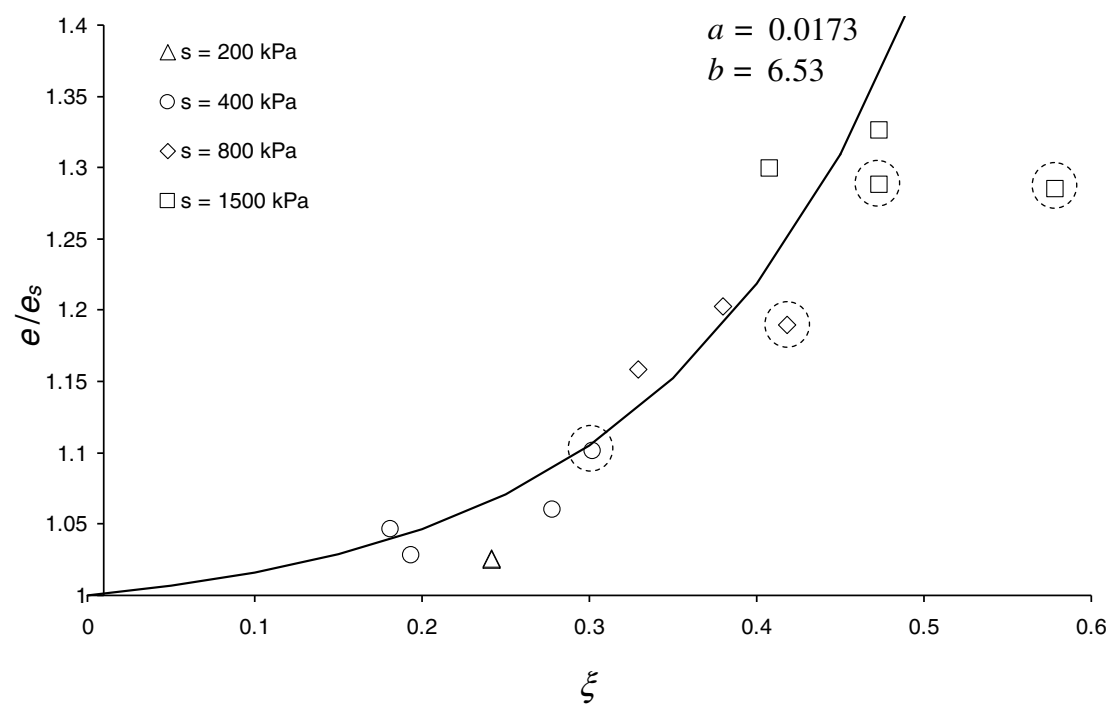

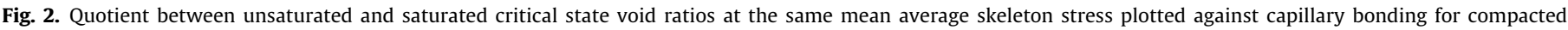
Jossigny silt (data by Cui [5]) together with interpolated capillary bonding function. 


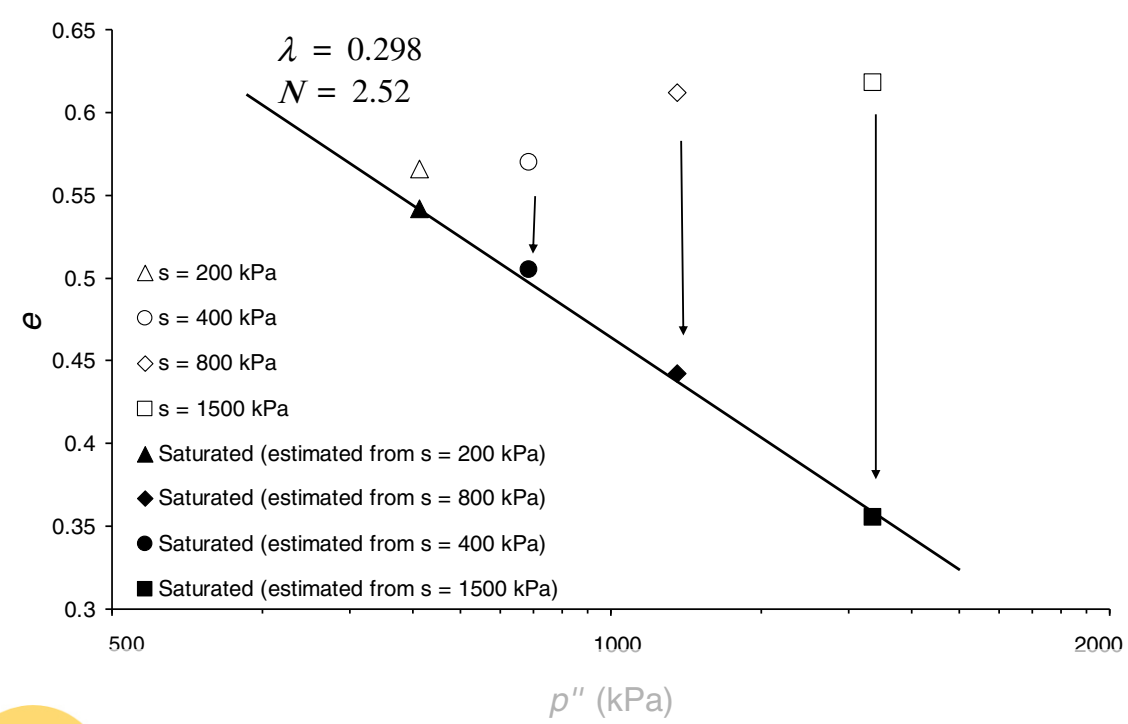

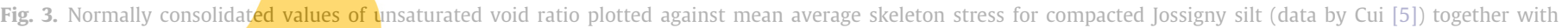
corresponding estimates of normally consolidated saturated values of void ratio and interpolated saturated normal compression line.

Inspection of Fig. 3 indicates that, as expected, the estimated saturated points fit a linear relationship in the semi-logarithmic plane $e-\ln p^{\prime \prime}$ and the slope $\lambda$ of such line is equal to 0.298 . This

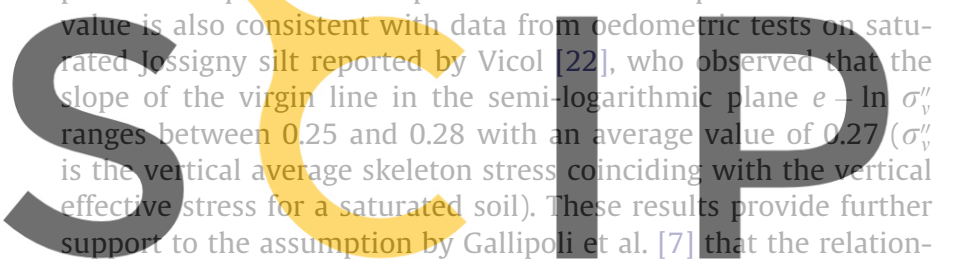

ship given by Eq. (6) is unique for both normally consolidated and critical stress states. It is worth noting here that the estimated

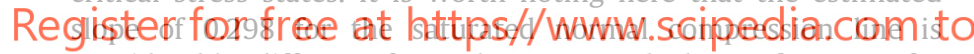
considerably different from the measured slope of 0.0932 for the saturated critical state line, which apparently contradicts experimental evidence suggesting that these two lines are parailei in the semi-logarithmic plane $e-\ln p^{\prime \prime}$. This discrepancy might be partly explained by the observation that, despite having assumed that critical state is attained in all triaxial tests performed by Cui [5], a considerable tendency to change in volume is still evident at the end of three out of four shearing stages used for the definition of the saturated critical state line in Fig. 1. Equally, a tendency to reduce in volume is still appreciable at the end of most constant suction shearing stages performed on unsaturated soil samples reported in Fig. 1. Notwithstanding such uncertainties about the achievement of critical state, the resulting capillary bonding function is still consistent with the expected trend and capable of predicting a realistic value of the saturated normal compression slope.

\subsection{Validation against data for Barcelona clayey silt [2]}

Barrera [2] carried a series of isotropic and triaxial shearing tests on Barcelona clayey silt under controlled suction and net stress. The isotropic tests involve rather complex paths with a combination of both loading/unloading at constant suction and wetting/drying at constant mean net stress. These also include one isotropic loading test under saturated conditions, which takes the soil well within the plastic region. This saturated test has been used in the present work to define the following equation of the saturated normal compression line to be used as a reference for the definition of the capillary bonding function:
$e_{\mathrm{s}}=N-\lambda \cdot \ln p^{\prime \prime}$

where the values of the parameters $N$ and $\lambda$ are equal to 0.934 and 0.0723, respectively.
Fig. 4 stiows this saturated normal compression line together
with the experimental plastic points used for its definition. These
points are identified in Fig. 4 by the label SAT-1, which is the same
label used in Barrera [2] to identify this test (note that the same
test labels as in Barrera [2] are used in all relevant figures of this
paper to facilitate cross-referencing with the original set of data).

Fig. 4 also shows additional data points that correspond to plastic behaviour of unsaturated soil samples subjected to isotropic stress

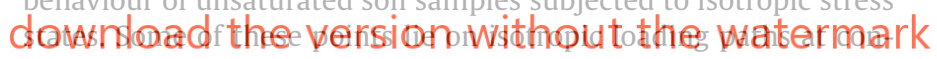
stant suction whereas other points belong to wetting paths at constant mean net stress (a point on a wetting path is assumed to represent a plastic state if the sample experiences compressive behaviour at that particular point). These data points are used in the present analysis to define the capillary bonding function for normally consolidated states regardless of whether they belong to a loading path or a wetting path. Due to the uniqueness of the normal consolidation surface in the void ratio-mean net stresssuction space (as first postulated by Alonso et al. [1]), these points are all representative of normally consolidated behaviour.

Fig. 5 plots the quotients $\frac{e}{e_{s}}$ between unsaturated and saturated void ratios (where the saturated void ratio is calculated from the normal compression line of Eq. (7) at the same average skeleton stresses as the unsaturated void ratio) against the capillary bonding $\xi$. Again, the points in Fig. 5 follow a clear trend that is interpolated by the capillary bonding function, which this time appears to follow a rather linear pattern. This is different from the case of Jossigny silt [5] shown in Fig. 2 and from the cases of Speswhite Kaolin clay [17] and [24], Bentonite/Kaolin clay [16] and Kiunyu gravel [20] shown in Gallipoli et al. [7], which all seem to suggest a more or less pronounced exponential increase of the ratio $\frac{e}{e_{s}}$ with capillary bonding $\xi$. The reason of this difference is likely to be found in the different soil fabrics and, in particular, in the distinct pore size distribution, which controls the number of water menisci that exist per unit volume of solid fraction at each given value of degree of saturation.

The data points in Fig. 5 are well fitted by Eq. (6), where the value of the material parameters $a$ and $b$ are equal to 1.11 and 0.492 , respectively. 


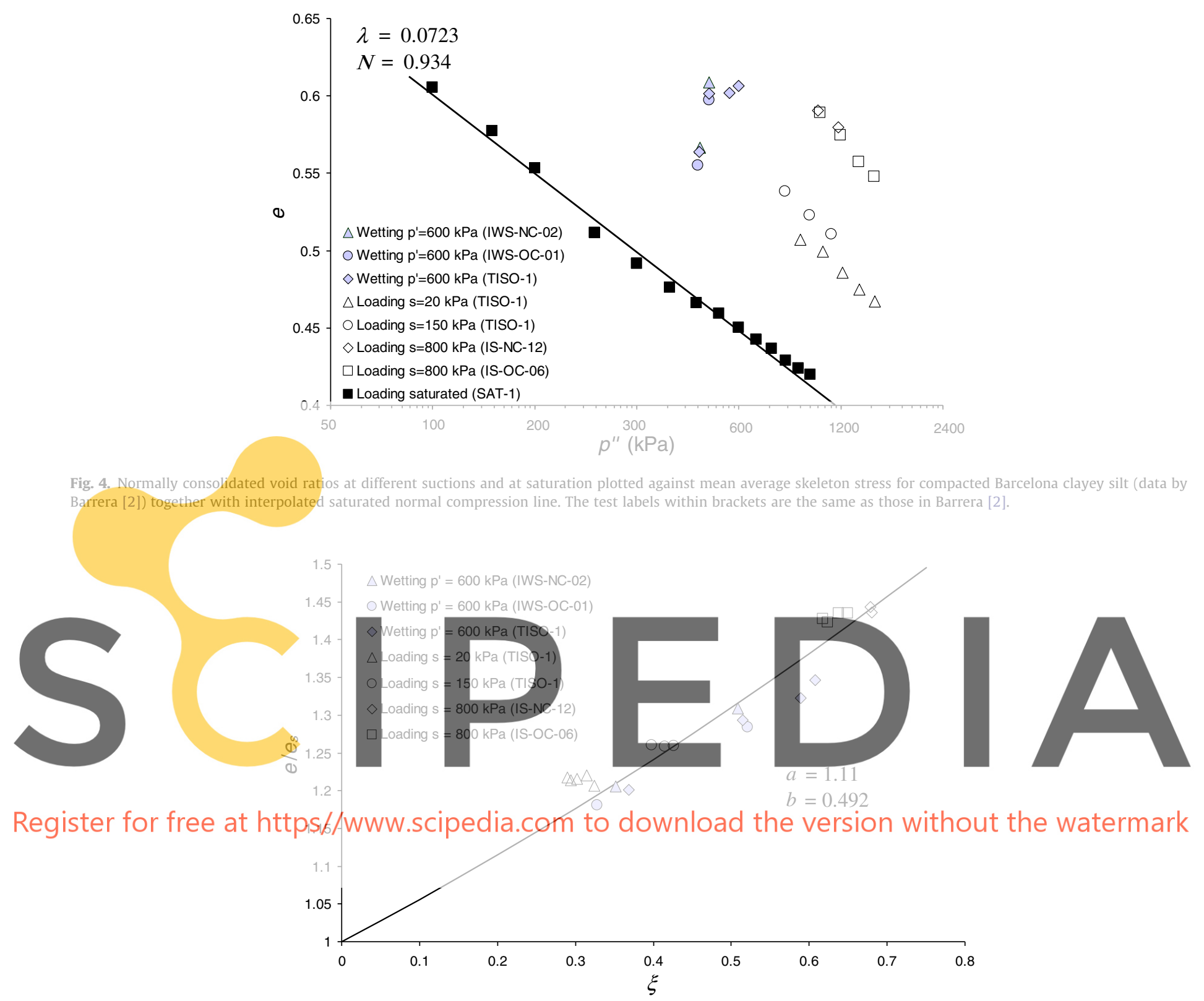

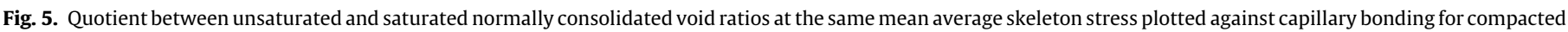
Barcelona clayey silt (data by Barrera [2]) together with interpolated capillary bonding function. The test labels within brackets are the same as those in Barrera [2].

Barrera [2] also performed six triaxial shear stages, five at a suction of $800 \mathrm{kPa}$ and one at a suction of $20 \mathrm{kPa}$. Some tests present rather complex consolidation paths prior to shearing, which involve both loading/unloading at constant suction and wetting/drying at constant mean net stress. In addition, Barrera [2] presents data from four saturated shearing tests but only two of these tests include information on volumetric strains and are reported here. All saturated and unsaturated shearing tests are assumed to load samples up to critical state.

Similarly to the logic used for the analysis of Jossigny silt, we assume that the capillary bonding function for normally consolidated conditions remains unchanged at critical states and can therefore be used to estimate the saturated critical state void ratios in correspondence of the mean average skeleton stresses attained at the end of the unsaturated shearing tests. The results of such analysis are shown in Fig. 6 where the unsaturated critical state void ratios from the six shearing tests are shown together with the corre- sponding estimates of saturated void ratios. The estimated saturated points fit the linear relationship of Eq. (5) in the semilogarithmic plane $e-\ln p^{\prime \prime}$ with the values of the parameters $\Gamma$ and $\psi$ equal to 0.867 and 0.0611 , respectively. Fig. 6 also shows that the critical state points from the two saturated shearing tests are consistent with the estimated saturated critical state line. This result further corroborates the assumption made by Gallipoli et al. [7] of the existence of a unique capillary bonding function at normally consolidated and critical states.

\section{Unsaturated critical shear strength}

In parallel with the investigation of the strain behaviour, previous research on unsaturated soils has also explored the existence of a relationship between the critical state shear strength and a single stress variable, as for saturated soils. One of the earliest contributions in this respect is due to Bishop and Blight [4], who 


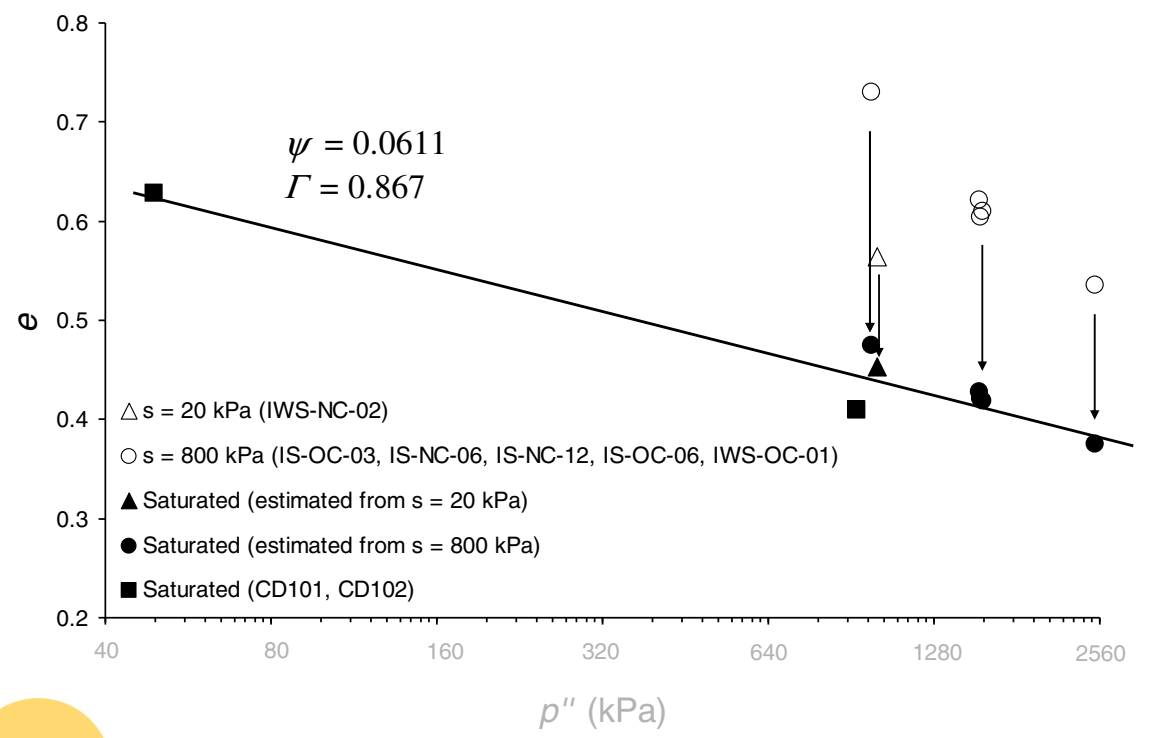

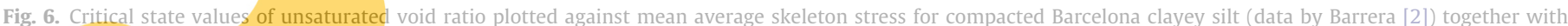

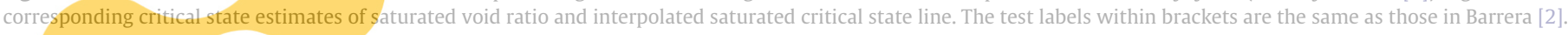

concluded that, unlike volumetric behaviour, the critical shear strength of an unsaturated soil may be reasonably related to a single stress given by Eq. (1) where $\chi$ is a material parameter depending on the degree of saturation. More ecently, Khalili and Khabbaz [12] surgested that the critical shear strength is uniquely relater to the stress of Eq. (1) where $\chi$ is a power function of the ratio between the current suction and the air-entry suction of the soil.
In this paper, the dependency of the critical shear strength on the average skeleton stress alone (2), where the $\chi$ parameter of Eq. (1) is tep the stress variable of Eq.

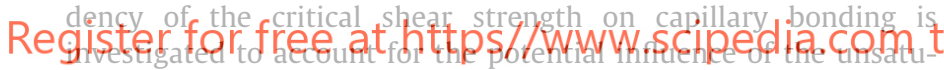
rated soil fabric at critical state. The motivation for such study stems from the observation, made in the previous section, that different values of void ratio, and therefore different material fabrics, can exist at critical state corresponding to the same mean average skeleton stress depending on the level of capillary bonding. This in turn poses the question whether such different fabrics also influence the critical deviator stress that the soil is capable of sustaining at a given mean average skeleton stress. The capillary bonding $\xi$

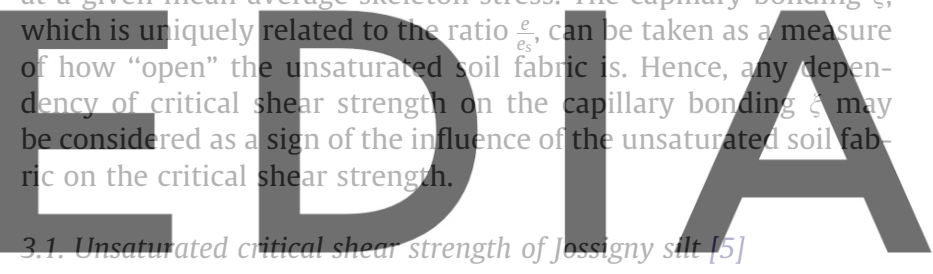

In Fio 7 the deviator stress at critical state is plotted against the
cow tests performed on saturated and unsaturated samples (at constant suctions of 200, 400, 800, and $1500 \mathrm{kPa}$ ) of compacted Jossigny silt [5]. Fig. 7 also shows a best-fit critical state line passing through the origin and having a slope $M$ equal to 0.84 . The circled points refer to tests where the deviator stress passes through a peak before

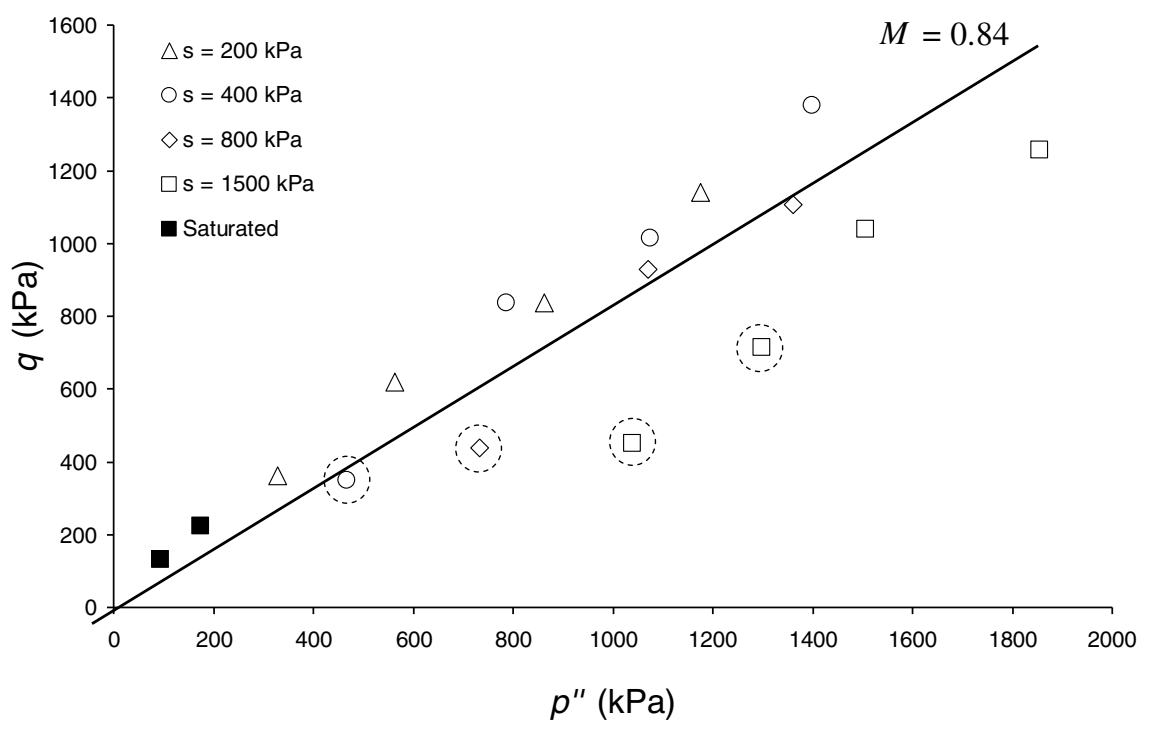


at different suctions together with interpolated critical state line. 


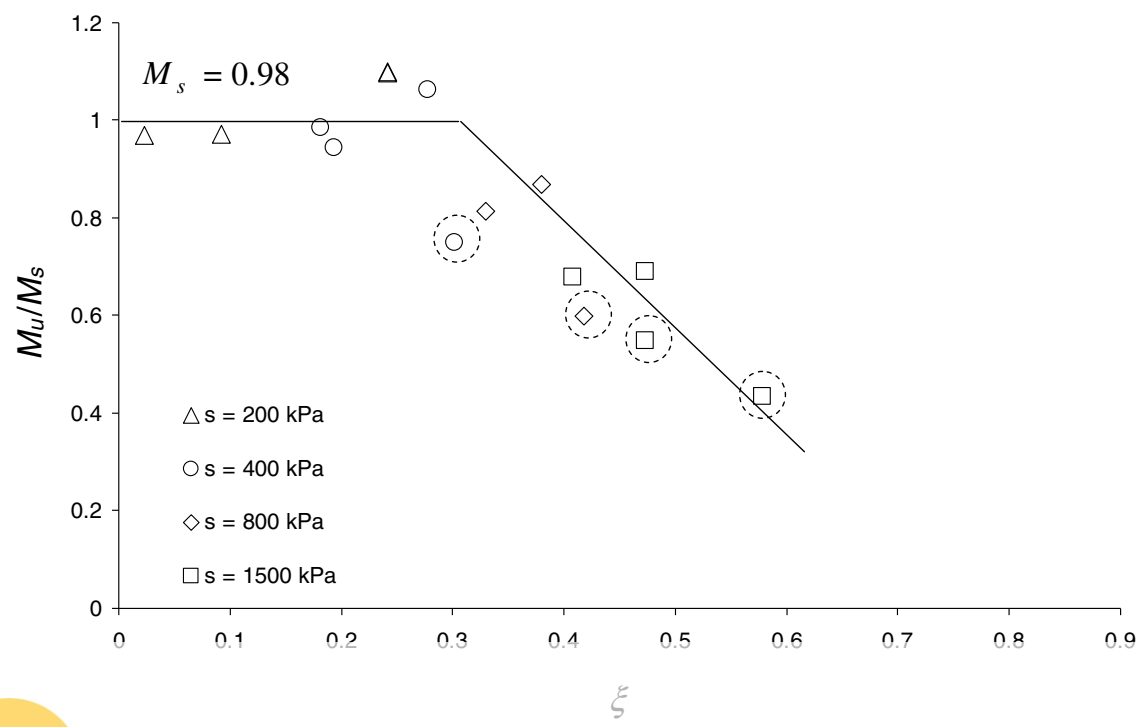

Fig. 8. Normalized critical state ratios plotted against capillary bonding for compacted Jossigny silt (data by Cui [5]) at different suctions.

achieving critical state and they have not been considered in the calculation of the best-fit line for the reason explained in Section 2.1.

Inspection of Fig. 7 indicates that the data present a moderate scatter at low suctions with a tendency to deviate substantially from the linear fit at the highest suction of $1500 \mathrm{kPa}$. The con siderable dispersion of the data may sugg deviator stress and mean average skel influenced, for unsaturated soils, different levels of capillary bonding. ossibility, the critical stress ratio the fa

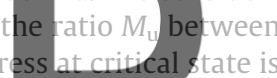
the fabric corresponding to order to investigate further $M_{1}$ normalized with respec to the slope of the saturated critical state line $M_{\mathrm{S}}$ (whose value is here estimated equal to 0.98), is plotted in Fig. 8 against the corre-

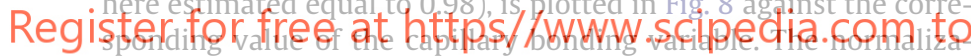

tion of the unsaturated critical stress ratio $M_{\mathrm{u}}$ with respect to the slope of the saturated critical state line $M_{\mathrm{S}}$ facilitates direct comparison among the different data sets presented in this paper.

Note that any error in the measurement of stresses at critical state is reflected in a corresponding error in the calculation of the stress ratio. The significance of the latter error increases mark- edly as the stress magnitude decreases and, for this reason, the two saturated points corresponding to the lowest stresses in Fig. 7 have not been included in the plot of Fig. 8 .

A clear trend can be identified in Fig. 8 whereby the normalized

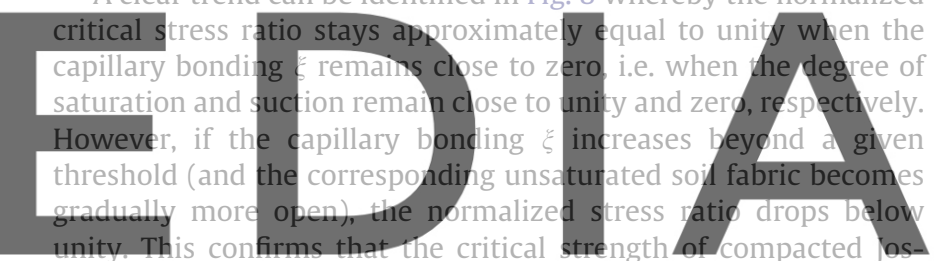

signy silt depends not only on the mean average skeleton stress dout bu sond the capillary bonding and, hence, on the "openness"

3.2. Unsaturated critical shear strength of Speswhite Kaolin [17] and [24]

Fig. 9 shows the deviator stress plotted against the corresponding mean average skeleton stress measured at critical state during

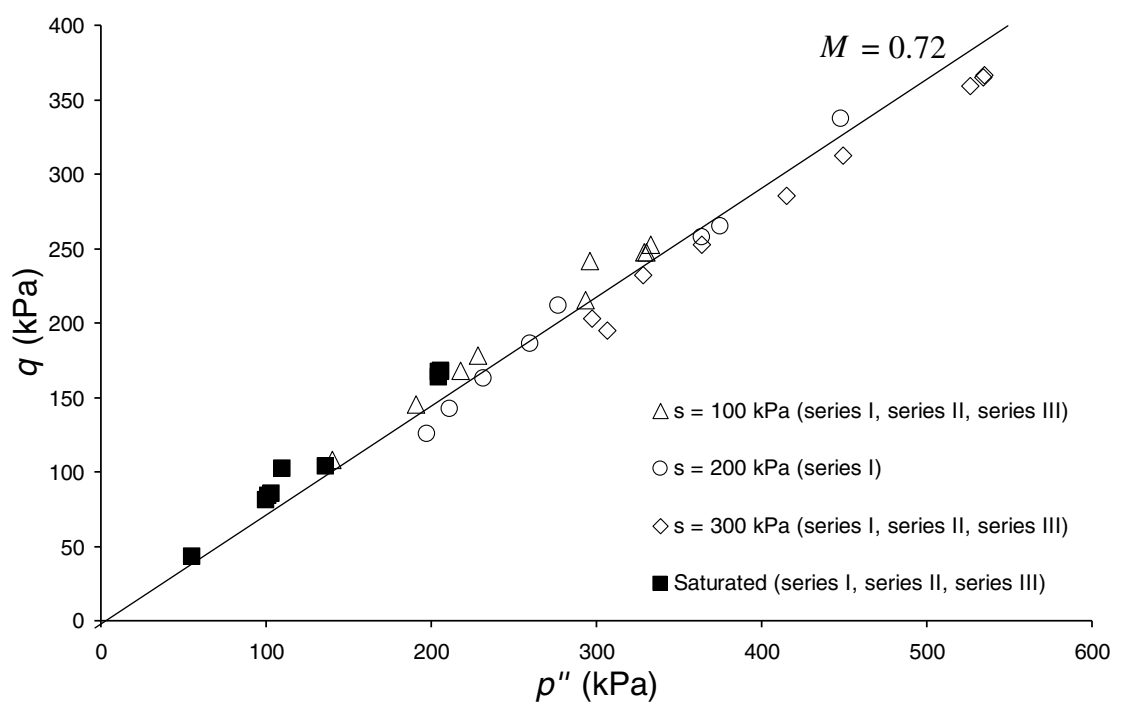

Fig. 9. Critical state values of deviator stress plotted against mean average skeleton stress for compacted Speswhite Kaolin (data by Sivakumar [17] and Wheeler and Sivakumar [24]) for saturated and unsaturated samples at different suctions together with interpolated critical state line. 
shearing tests on saturated and unsaturated samples (at constant suctions of 100,200 , and $300 \mathrm{kPa}$ ) of compacted Speswhite Kaolin performed by Sivakumar [17] and Wheeler and Sivakumar [24]. The different experimental series in Fig. 9 are associated to different procedures adopted for the compaction of Speswhite Kaolin samples at the same water content, as explained in Wheeler and Sivakumar [24]. Fig. 9 also shows a best-fit critical state line passing through the origin (having a slope $M$ equal to 0.72 ), which indicates that the data follow a relatively clear linear trend. Although the points in Fig. 9 present some degree of scatter, the dispersion is significantly less than that observed in Fig. 7 for Jossigny silt.

The potential dependency of the critical strength on the unsaturated soil fabric generated by capillary bonding is considered in Fig. 10, where the critical stress ratio $M_{\mathrm{u}}$ of individual samples is normalized with respect to the slope of the saturated critical state line $M_{\mathrm{s}}$ (whose value is here estimated equal to 0.80) and plotted against the corresponding value of the capillary bonding $\xi$. Note that Fig. 10 does not include the five saturated points correspond- ing to the lowest stresses in Fig. 9 because the normalized critical state ratios for these points are likely to be affected by relatively large errors as explained in Section 3.1.

Inspection of Fig. 10 shows a decrease of the normalized critical stress ratio with increasing values of the capillary bonding $\xi$. This confirms the trend in behaviour already observed in the previous section, although the rate of decrease appears to be considerably less for Speswhite Kaolin in comparison to Jossigny silt.

\subsection{Unsaturated critical shear strength of Barcelona clayey silt [2]}

Fig. 11 shows the deviator stress plotted against the corresponding mean average skeleton stress measured at critical state from the shearing tests performed by Barrera [2] on saturated and unsaturated samples (at constant suctions of $20 \mathrm{kPa}$ and $800 \mathrm{kPa}$ ) of compacted Barcelona clayey silt.

Inspection of Fig. 11 indicates that, throughout the experimental stress range, the data for Barcelona clayey silt present consider-

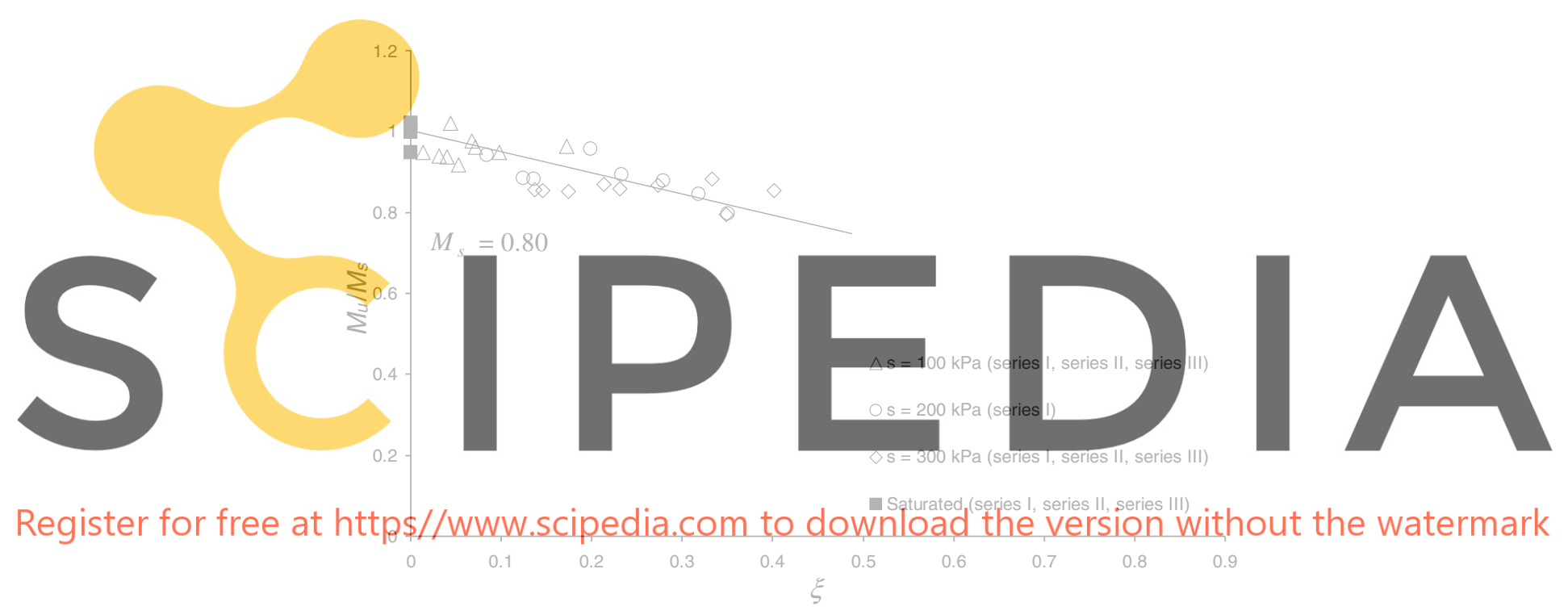

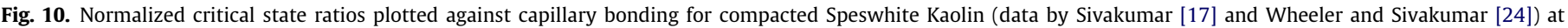
different suctions.

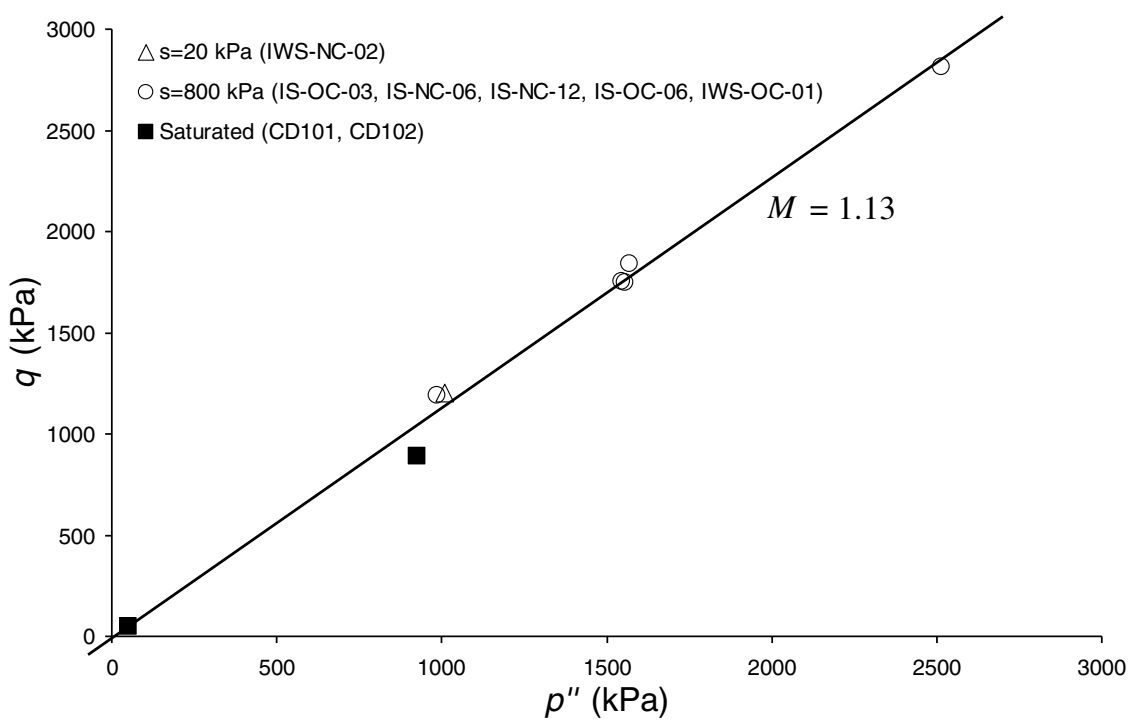

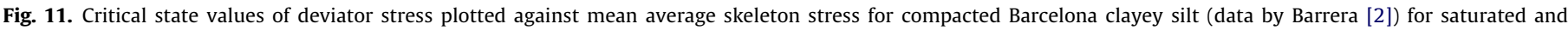
unsaturated samples at different suctions together with interpolated critical state line. The test labels within brackets are the same as those in Barrera [2]. 


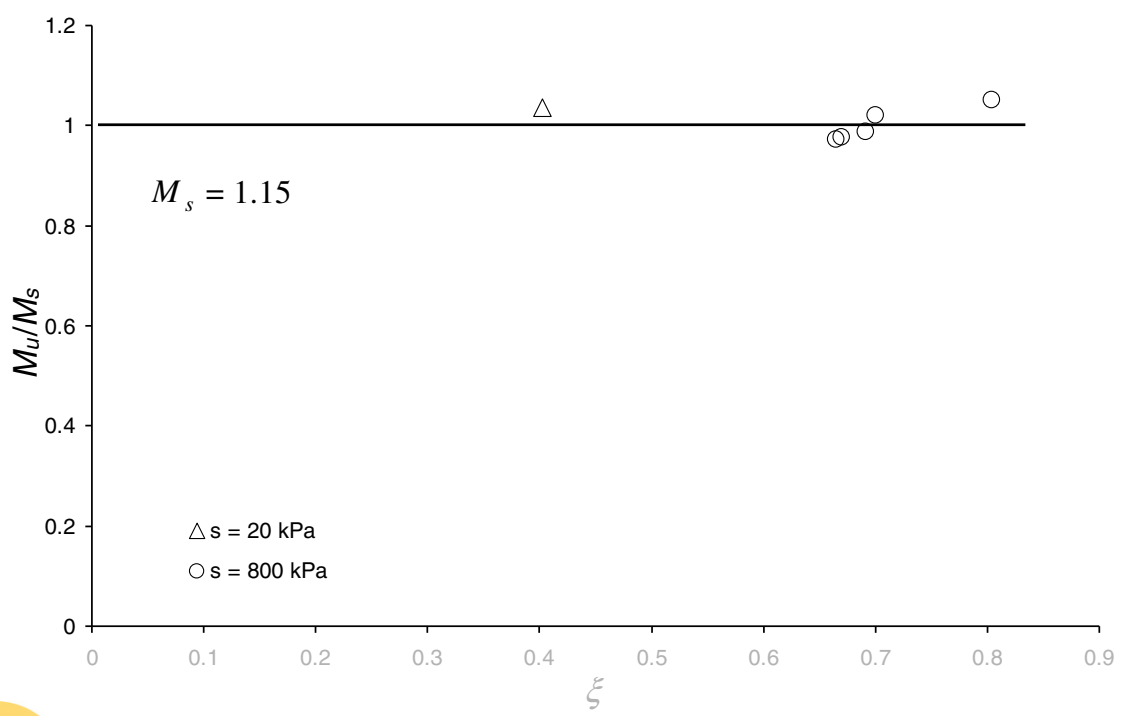

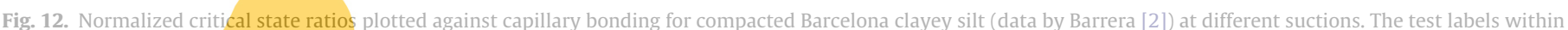
brackets are the same as those in Barrera [2].

ably less scatter in comparison to the data for Jossigny silt and Speswhite Kaolin shown in Figs. 7 and 9, respectively, although the number of data points available for Barcelona clayey silt is sig1

nificantly less than for the other tyo

are also well interpolated by a linear

point at suction of $800 \mathrm{kPa}$ refers

shearing, to a wetting/drying cycle

from $800 \mathrm{kPa}$ to $10 \mathrm{kPa}$ and back to $800 \mathrm{kPa}$

tropic net stress state. Yet this data point fits th

as for the other points and the hydraulic cycle prior to shearing

does not seem to produce any anomaly in the relation between

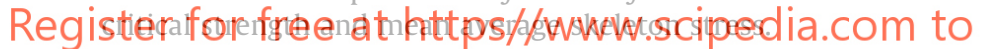

The points shown in Fig. 11 are used to calculate the corresponding values of the critical stress ratio $M_{\mathrm{u}}$ normalized with respect to the slope of the saturated critical state line $M i_{s}$ (assumed here to be equal to 1.15), which are plotted in Fig. 12 against the capillary bonding $\xi$. Similarly to the previous data sets, the normalized critical stress ratios shown in Fig. 12 do not include the two saturated tests at the lowest stresses reported in Fig. 11.

As expected from the limited scatter in Fig. 11, the normalized critical state ratio stays approximately equal to unity over the whole experimental range. This seems to suggest that, for this particular soil, the unsaturated fabric at critical state has little influence on the corresponding strength. Such behaviour is different from that observed for Jossigny silt and Speswhite Kaolin in Sections 3.1 and 3.2, respectively. It is worth noting that the analysis of the volumetric behaviour in Section 2.1 also shows an atypical form for the capillary bonding function, which appears to be closer to a straight line rather than to the characteristic exponential law observed for all other materials. At this stage it is only possible to speculate that these distinctive aspects of behaviour in terms of both critical strength and volumetric deformation originate from the same cause and might be related to the particular evolution of capillary bonding during changes of degree of saturation.

\section{Conclusions}

Two sets of data from laboratory tests on compacted Jossigny silt and compacted Barcelona clayey silt performed by Cui [5] and Barrera [2], respectively are analysed in the light of the consti- tutive model proposed by Gallipoli et al. [7]. The results for each soil confirm the existence of a unique function, valid for both normally consolidated and critical stress states, linking the ratio be-

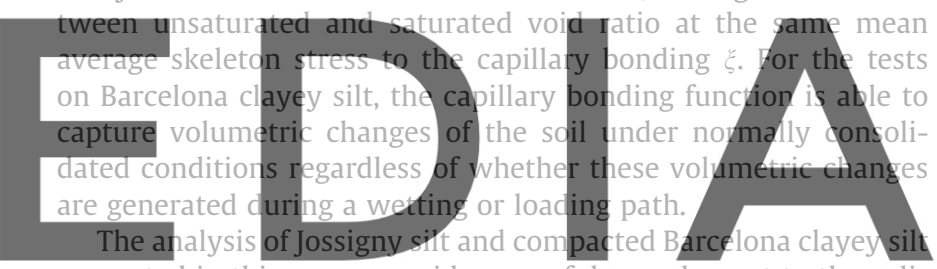
presented in this paper provides a useful complement to the validation of the model by Gallipoli et al. [7] because these two soils

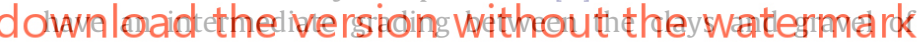
the experimental programmes considered in Gallipoli et al. [7].

The second part of the paper analyses the relationship between unsaturated critical shear strength, mean average skeleton stress and capillary bonding $\xi$ based on the previous two sets of experimental data, with the addition of a further data set from laboratory tests on compacted Speswhite Kaolin performed by Sivakumar [17] and Wheeler and Sivakumar, [24]. The analysis indicates that, for Jossigny silt and Speswhite Kaolin, the normalized critical stress ratio (i.e. the ratio between deviator stress and mean average skeleton stress at critical state, normalized with respect to the slope of the saturated critical state line) appears to decrease when the capillary bonding $\xi$ increases and such trend is more marked for the former data set with respect to the latter one. This corresponds to the observation that, as the capillary bonding $\xi$ increases, progressively larger void ratios are attained at critical state under any given level of mean average skeleton stress. Therefore, for larger values of the capillary bonding $\xi$, a more "open" critical state fabric exists and this is likely to have an effect on soil strength.

This behaviour, however, is not apparent from the analysis of Barcelona clayey silt, which shows no variation of the normalized critical stress ratio with the capillary bonding $\xi$. In this case, unlike Jossigny silt and Speswhite Kaolin, the critical strength is little affected by the unsaturated fabric and is therefore suitably modelled by assuming a dependency on the average skeleton stress alone. The Barcelona clayey silt also shows an atypically linear capillary bonding function in contrast with the characteristic exponential trend of the capillary bonding functions of all other materials. Both such distinctive aspects of behaviour may be related to the partic- 
ular evolution of capillary bonding during changes of degree of saturation in this material.

Finally, it is worth noting that the description of the critical shear strength presented in this paper can be recast according to the formulation presented in Toll [20] and Toll and Ong [21]. These authors used two independent coefficients $M_{\mathrm{a}}$ and $M_{\mathrm{b}}$, depending on degree of saturation, to relate the variation of deviator stress at critical state with mean net stress and suction, respectively. It is easily shown that the dependency of deviator stress at critical state on mean average skeleton stress and capillary bonding proposed in this paper results in the calculation of the two coefficients $M_{\mathrm{a}}$ and $M_{\mathrm{b}}$ as

$M_{\mathrm{a}}=M_{\mathrm{s}} \frac{M_{\mathrm{u}}}{M_{\mathrm{s}}}(\xi)$

$M_{\mathrm{b}}=S_{\mathrm{r}} M_{\mathrm{s}} \frac{M_{\mathrm{u}}}{M_{\mathrm{s}}}(\xi)$

where $S_{r}$ is the degree of saturation and $M_{u}(\xi)$ is the function relating the normalized critical stress ratio to the capillary bonding $\xi$ as shown in Figs. 8, 10 and 12 for Jossigny silt, Speswhite Kaolin and Barcelona clayey silt, respectively.

For Jossigny silt and Speswhite Kaolin, both coefficients $M_{\mathrm{a}}$ and $M_{\mathrm{b}}$ decrease for decreasing values of degree of saturation. This can be easily understood from Eqs. (8) and (9) taking into account the particular form of the function $\frac{M_{u}}{M_{u}}(\xi)$ for these two materials (see Figs. 8 and 10) and the fact that the capillary bonding $\xi$ increases for decreasing value of degree of saturation.

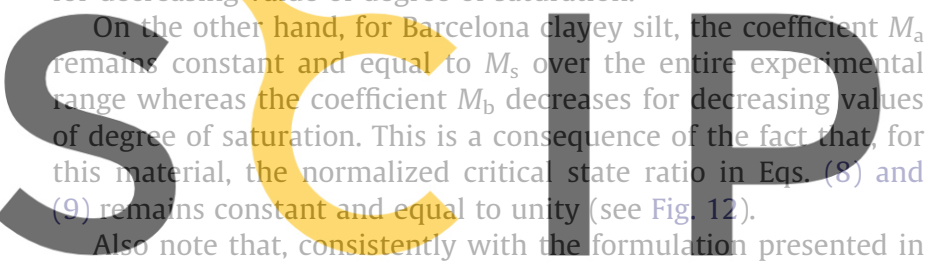

Toll [20] and Toll and Ong [21], the coefficient $M_{\mathrm{b}}$ is equal or smallẹ than the coefficient $M_{a}$ for any value of degree of saturation be-

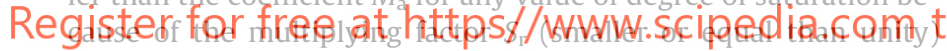
present in Eq. (9).

\section{Acknowledgements}

The support of the European Commission via the "Marie-Curie" Research Training Network MUSE (Mechanics of Unsaturated Soils for Engineering) - Contract No. MRTN-CT-2004-506861 - is gratefully acknowledged.

\section{References}

[1] Alonso EE, Gens A, Josa A. A constitutive model for partially saturated soils. Géotechnique 1990;40(3):405-30.

[2] Barrera M. Estudio experimental del comportamiento hidro-mecánico de suelos colapsables. Thesis doctorial, Universitat Politecnica de Catalunya, Spain; 2002.

[3] Bishop AW. The principle of effective stress. Teknisk Ukeblad 1959;106(39):859-63.

[4] Bishop AW, Blight GE. Some aspects of effective stress in saturated and partly saturated soils. Géotechnique 1963;13(2):177-97.

[5] Cui YJ. Etude du Comportement d' un limon compacte non sature et da sa modelisation dans un cadre elasto-plastique. These de doctorat, Ecole Nationale des Ponts et Chaussées, France; 1993.

[6] Fisher RA. On the capillary forces in an ideal soil correction of formulae given by WB Haines. J Agric Sci 1926;16(3):492-505.

[7] Gallipoli D, Gens A, Sharma RS, Vaunat J. An elasto-plastic model for unsaturated soil including the effect of saturation degree on mechanical behaviour. Géotechnique 2003;53(1):123-35.

[8] Hutter K, Laloui L, Vulliet L. Thermodynamically based mixture models for saturated and unsaturated soils. Mech Cohes Frict Mater 1999;4:295-338.

[9] Jennings JE, Burland JB. Limitation to the use of effective stress in partly saturated soils. Géotechnique 1962;12(2):125-11.

[10] Jommi C. Remarks on the constitutive modelling of unsaturated soils. In: Proceedings international workshop on unsaturated soils, Trento; 2000. p. 139-53.

[11] Karube D, Kawai K. The role of pore water in the mechanical behavior of unsaturated soils. Geotechn Geolog Eng 2001;19:211-41.

[12] Khalili N, Khabbaz MH. A unique relationship for $\chi$ for the determination of the shear strength of unsaturated soils. Géotechnique 1998;48(2):1-7.

[13] Lewis RW, Schrefler BA. The finite element method in the deformation and consolidation of porous media. Chichester: Wiley; 1987.

[14] Loret B, Khalili N. An effective stress elastic-plastic model for unsaturated porous media. Mech Mater 2002;34:97-116.

[15] Nuth M, Laloui L. Effective stress concept in unsaturated soils: clarification and


the planes of shear. In: Proceedings 1 st international conference on soil mechanics and foundation engineering, Camb., Mass 1; 1936. p. 54-6.

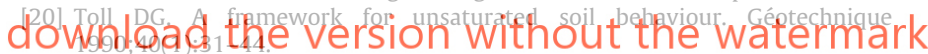

[21] Toll DG, Ong BH. Critical-state parameters for an unsaturated residual sandy clay. Géotechnique 2003;53(1):93-103.

[22] Vicol T. Comportement hydraulique et mecanique d' un sol fin non sature application a la modelisation. These de doctorat, Ecole Nationale des Ponts et Chaussées, France; 1990.

[23] Wheeler SJ, Sharma RS, Buisson MSR. Coupling of hydraulic hysteresis and stress-strain behaviour in unsaturated soils. Géotechnique 2003;53(1):41-54

[24] Wheeler SJ, Sivakumar V. Influence of compaction procedure on the mechanical behaviour of an unsaturated compacted clay. Part 2: shearing and constitutive modelling. Géotechnique 2005;50(4):369-76. 